\title{
Translation as Craft, as Recovery, as the Life and Afterlife of a Text: Sujit Mukherjee on Translation in India
}

\author{
Elena Di Giovanni \\ University of Macerata, Italy
}

That is how we learnt English - through translation and re-translation, through transcription in Hindi and annotation in Bangla, through learning grammatical rules by rote and English idioms by heart (the latter process popularly known as "by hearting"). Out of such remembering and recording will come India's theories of translation. (Mukherjee, 2002: 30)

Sujit Mukherjee was born in 1930 in Patna and died in Secunderabad in 2003. He grew up in his original town, then moved to Delhi, Hyderabad, Pune and other Indian cities. He was both a prolific writer and an affirmed translator. As an author, his main interests were in literary history, American studies and Indian literatures. He also wrote about two passions and much beloved activities, i.e. cricket and translation. Most of his essays on translation were gathered in two volumes: Translation as Discovery (1981) and Translation as Recovery (posthumous, 2004). The contributions which appear in these books, as well as those published elsewhere, present abundant information and countless reflections on the historical, social and cultural role played by translation activities in India. For the purpose of this paper, we shall refer almost exclusively to the second book, as it is the more comprehensive of the two.

As Harish Trivedi rightly observes in his introduction to Translation as Recovery, Mukherjee was able to offer "a modest, thoughtful, deeply engaged, closely attentive, widely contextualized, toughly interrogative and highly readable account of a great variety of issues to do with translation in India" (Trivedi, 15). He trained as a student of English literature, and grew up wishing to be a university teacher of English, thus combining the best of Indian and English sensibilities, expressing his Indianness and exploring the changes of the cultures and languages of India through an Englisheducated mind and sensibility. With the linguistic creativity typical of India's brilliant academics who have worked with and on translation - of which both Mukherjee and Trivedi are outstanding examples - Harish Trivedi further defines Mukherjee in the following terms: "He was a bhadralok gentleman. His mots were acutely juste while they were also full of jouissance, of a rasika's enjoyment of life, language and literature. 
Deeply rooted in our own culture, he developed an intellectual grace and rigour with which he negotiated the West in his own terms" (15).

Sujit Mukherjee's negotiation with the West can be reconstructed through his witty writings on translation and also through his creative use of the English language, to such an extent that neologisms abound and existing words are often given creative meanings. A good example of the vivacity of his thought and use of English is provided in the introductory quotation above, where he uses seven different words to refer to the vast and varied number of translation-related activities in India, starting with the most common - translation - and finishing with 'remembering' and 'recording,' two words which so well express the uniqueness of India's history of translation. Mukherjee's linguistic and conceptual creativity is also exemplified by some of his powerful statements about the status of the Indian languages vis-à-vis English and its original context(s), as well as about the postcolonial relationships established between Western and Indian scholars, with the prefix 'post' simply meaning here 'subsequent'. 'With his typically constructive rather than critical attitude, Mukherjee defined the complex, multilingual situation of India as the Bower of Babel, which dismisses the negative connotation inherent in the use of Tower and the possible political implications of its replacement by Power (as in the Power of Babel), ${ }^{2}$ to metaphorically define India as a cozy shelter for languages and cultures. Similarly, but with an extra touch of humour, Mukherjee upturned the Western-centred view of world geography by naming the UK India's Middle West, as opposed to the Western-originated definition of Middle East, and by defining the USA in its entirety as the Far West, thus metonymically expanding the Western, Hollywood-inspired view of it.

It is precisely on these and other profound yet simple, detailed yet subtly ironical reflections on translations, languages, cultures and geographies by Sujit Mukherjee that this article is based. Its main aim is to trace the evolution and impact of translation in India, before and after colonial days, through the eyes and mind of a privileged observer.

\footnotetext{
${ }^{1}$ Such a clarification is needed in respect of Mukherjee's position, which was clearly oppositional to the most typical, often self-piteous postcolonial attitudes. See Translation as Recovery, 15, 52, 145.

2 Several books have been published with the title The Power of Babel, which discuss the impact, reciprocal influence and socio-political potential of languages the world over (John McWhorter, 2003) or in specific areas (Ali A. Mazrui and Alamin M. Mazrui, 1998). In his introduction to Sujit Mukherjee's posthumous volume, Harish Trivedi refers specifically to McWhorter's 2003 book.
} 
Embarking on a joint exploration of Mukherjee's thoughts and India's translation story entails expanding the familiar, Western-driven boundaries of the notion of translation to let in all those activities which derive from, border with and merge into translation. This, in turn, leads to a broadening of the terminology used to refer to such complex phenomena: rewriting, new writing, transcreation, recreation - to mention but the main ones - will all play a role within this account.

Although Mukherjee never really did so in his writings, this article will follow a diachronic perspective, at least in its first two sections, focusing first on India before the British, then moving on to the advent of English in India and its aftermath in linguistic, translational and cultural terms. A third and final section reflects on the state of the art and future of translation in India, as well as on the changing role of English, bringing together some of Mukherjee's reflections and those offered by three outstanding Western scholars.

\section{India before the British}

What we don't yet have in India is a theory or theories of translation. This may be because we have been practising translation for so many years - so many centuries, in fact - that we forgot to stop and theorise. (Mukherjee, 2004: 36)

Since the days in which Sanskrit was the official language of writing and the scriptures, written translations were produced from the latter into most Indian languages. Sanskrit, therefore, was the language of production of literary and religious texts, whose translation into the regional languages, as has been said by several scholars (see, for instance, Kumar), contributed to the creation of a "panIndian ethos" (Kumar, 18).

Besides these processes, the history of India has also been strongly characterized by the development of the so-called bhashas, the modern Indian languages. Their use in different areas of India - or their coexistence - went hand in hand with their unavoidable interaction. This has obviously implied constant processes of interlingual translation, practiced by most Indians on a daily basis, for all sorts of functional purposes. This 'life in translation' is one of the main reasons Mukherjee finds for the lack of explicit theorization: Indians have been so constantly engaged in translation that they did not worry about theorizing about it. Another Indian scholar, Samantak Das, has also reflected upon the lack of theories of translation in India and the proliferation in the West, by stating: 
So far, it seems to me that theorists of translation have, for the most part, been products of a) monolingual cultures (though they may be competent in several languages themselves); and b) Western metropolitan academies where there is one, dominant, monolingual discourse to which they must submit. [...] If a new body of theory and praxis is to emerge from India, it must take into account our own multilingual selves, which are constantly negotiating - with varied degrees of competence and success - between different languages and language systems. (36)

Das points to another essential issue related to the lack of sound theories of translation in India: the complexity of translation fluxes, the ever-shifting relations of identities, languages and cultures which make theorization all the more difficult. And yet, what seems to have been overlooked by both Mukherjee and Das is the existence of prefaces, comments, and appendices which have accompanied at least written translations, performed through the centuries and not only from Sanskrit. This brings us back to the first typology of translational activities highlighted in this section - from Sanskrit into the regional languages - and leads us to clearly see that, notwithstanding its overall complexity, translation in India before colonization took two main forms: between the regional languages, it was performed mainly in oral form for practical, everyday interaction purposes; from Sanskrit into the bhashas it was mainly written, encompassing religious, literary and educational purposes. The two typologies share an essential feature: all translational activities before colonization were characterized by positive dynamism, vivacity, creativity. The latter is, however, best traced in the history of written translations from Sanskrit. As Ravi Kumar points out, "In the ancient period the purpose of translation was totally different from today. Most of the time, Sanskrit texts used to be changed in the form (rupantar) into several languages (bhashantar), or they were called anwvad, i.e. coming after, following after. This meant little emphasis on maintaining the originality of the source text” (Kumar, 19).

Kumar's statement points to a major difference from contemporary translation practices, whereby proximity to the source text is a priority much more than it used to be in the past. ${ }^{3}$ Fidelity to the source was far less prominent than creativity in drafting the target text, an attitude which is essential to understanding the notion of 'transcreation'. First defined and used in India, then adopted globally by translation and literary theorists, this notion was coined to refer to the ancient, creative

\footnotetext{
${ }^{3}$ Kumar refers here to activities and practices carried out more than 2000 years ago.
} 
reproduction of religious texts written in Sanskrit, such as the Vedic truths, in as many Indian languages as possible (Gopinathan), with the aim to make these texts easily accessible for laypeople throughout India. The practice of transcreation passed from religious to literary texts, so much so that even when, as Mukherjee says, India was still called Jambudiva (in Bharat), literary compositions originating in one language were recomposed by retelling or rewriting them in another language. This process, for which Mukherjee uses the expression "translation as new writing" (Mukherjee, 2004: 34), reinforces the view of written translational activity in India as highly dynamic and prolific, which nonetheless runs parallel to the other typology, i.e. the interlingual, daily interaction of people speaking different languages throughout the country.

The highly creative potential, the freedom from imitation, the vivacity and multiplicity of translation processes in pre-colonial days lead Mukherjee to define translation as 'craft.' While rejecting the occasionally evoked notion of art in relation to it, Mukherjee locates within the definition of craft all the creativity of translational processes:

I feel uneasy when I hear talk about 'the art' of translation. My unease springs, among other apprehensions, from the fear that by talking about the art of translation we may be surreptitiously seeking to defend translation against the usual charge, namely that it is a secondary activity - secondary, that is, in rank to an activity such as creative writing; secondary also in activation, because translation must always follow after. Whereas in my own perception, underlined by some practice, translating a literary work stands very close and nearly equal to the writing of it. (2004: 37)

Besides the inherent reference to translation as a creative activity, which comes with the very use of the word 'craft', Mukherjee goes further, stating that translation stands very close and nearly equal to original, literary writing. This powerful assertion, which views translation in a positive light, permeates all of Mukherjee's writings on translation, where he never fail to express support for the translator's creative job.

Craft, as Mukherjee says, needs no defence. By the same token, translation and translators do not need to defend themselves from charges of being secondary, derivative, ancillary. 
Further on in the essay quoted above ("The craft, not sullen art of translation," in Translation as Recovery), the author provides one more reason for preferring to call translation craft rather than art. In this case, he refers more specifically to the everyday practice of interlingual communication, mainly performed orally and for eminently practical purposes. Although considering this typology equally valuable and important, Mukherjee states that "to regard such a habit as art would be to claim an unwarranted distinction. That habit can be refined into a craft, rather than exalted to an art" (2004: 38). Everyday functional translation shares in the creativity, originality, and spontaneity of written translation. It cannot be called an art but it does preserve the essence of craftsmanship. And thus the circle of reflections on the host of translational activities carried out in India before colonization is closed. On a positive note.

\section{India and the advent of English}

With the advent of English, the context and role of translation in India changed radically. (Mukherjee, 2002: 26)

As Mukherjee observes, the translation landscape morphed rapidly into a thoroughly new scenario with British colonization. A good share of the positive, creative atmosphere of translational activities carried out before the colonial days seems to have been shattered by this major historical and cultural landmark. As in many other colonial contexts, the British took control of India thanks to a skilful use of their language, whose global influence and hegemony finds its origins precisely in colonial times. However, to try to grasp the nature and extent of the changes in terms of translational practices, let us follow Mukherjee's reflections on this issue. The following excerpt, though positive in essence, outlines the three major areas of change:

The advent of English and its growing ascendancy have changed the translation scene as never before. The colonial times have been our most productive, where literary translation is concerned. At least three areas of translation grew and prospered. One, translation of Indian literary texts into English; two, translation of English language texts into Indian languages; three, translation from one Indian language into another. The trajectory of each kind was different, but the total outcome was a tremendous enrichment of our literary culture. (2004: 23-24) 
Indeed, changes were radical and bound to initiate even more radical developments over time. The major alterations in the translation landscape were political and directional: the role of Sanskrit came to be progressively reduced and English took over as a 'master language', i.e. the language of most translation processes. This linguistico-political change was matched by what was to become, in time, a reversed directionality. If Sanskrit used to be the source of most translations (transcreations), English came to be the predominant target language, the recipient of Indian texts. Although up until the late $19^{\text {th }}$ century a host of translations involving English were still translated from the latter into the Indian languages, mainly for educational purposes, in the following century English took over as a target language, and not without implications, as we shall see further on. Moreover, in time English was also more and more frequently a pivot language in translations between the modern Indian languages. With reference to this phenomenon in his own days, Mukherjee says, "I hesitate to believe this, but most agencies that require intra-Indian language translations tend to work from what are slavishly called master copies in English" (2004: 30).

Thus, it seems that, differently from Sanskrit, English managed to somehow control the overall translation circuit, becoming by far the most powerful target but also source language. Moreover, its overwhelming role in translation processes also meant covering most purposes and domains: if the translation of literary and scriptural texts was most frequently performed from the Indian languages into English, the translation of textbooks, manuals of different types, as well as scientific treatises, by Europeans and Indians, was commonly performed from English into the Indian languages.

In our resolve to retrace Mukherjee's work within the trajectory of Indian translation, by referring mainly to the domain of literature, we shall hereafter focus on the flourishing of translations into English from the Indian languages, which was established as a regular practice in the second half of the $18^{\text {th }}$ century. As has been briefly mentioned above, this ever-growing trend has had a number of implications, which impinge on the concept of translation as craft but, most of all, have contributed to redesigning the ethics of translation in India. Let us once again follow Mukherjee who, in the excerpt below, first of all reflects on the different roles played by Sanskrit before, and English after, colonization. If Sanskrit had been a benevolent mother, giving birth to new creations, English came to be a master, absorbing texts, ideas and traditions. 
Sanskrit, in postcolonial terminology, could probably be regarded as a master language, which is precisely what English became for Indians in the $19^{\text {th }}$ century and thereafter, with translators into English seen as interventionists assuming power over Indian-language writers. Pre-colonial India recognized no such relationship and, rather than master or mistress, Sanskrit performed like a mother giving birth to many literary works in other languages. That is, the bent of translation was from Sanskrit rather than into Sanskrit and, the translators or transcreationists exercised no political superiority over the original authors. (2004: 45)

Thus, as Mukherjee states, transcreationists gave way to masters; creativity gave way to power exertion. However, as he explains in the next excerpt, the power English exerted over translation processes went through different stages, ultimately ending in the hands of Indians:

When the English language came to India and, from the $18^{\text {th }}$ century onwards, gave clear signs of wanting to stay on, one clear signal was through acts of translation. Starting with Sir William Jones's translation of Sacoontala, nearly all major literary works in Sanskrit and Old Tamil, Pali and the Prakrits have been translated into English. The late $18^{\text {th }}$ and $19^{\text {th }}$ century translations were done mostly by British scholars of Indology, a few by Americans. From the late $19^{\text {th }}$ century onwards Indians joined the enterprise in growing numbers. Also growing in numbers were translations of literary texts from more recent times, coming right down to contemporary authors. As a result, we have today a sizeable quantity of Indian literature of every age in English translation, waiting to be read and written about, reviewed and revised, studied and taught. (2004: 46)

English first conquered Indian-language textual production through mother tongue translators, either acting on the Indian territory or, occasionally, from England. Then, as Mukherjee observes, translation into English was increasingly practiced by Indians, a trend which brought about the most significant changes and opened to further developments, such as the rise of IEL, Indian English Literature.

To sum up what has so far emerged from Mukherjee's remarks on the postcolonial translation landscape in India, the main mutations brought about by the British colonization have been: 
1) the constant decrease of written translations between the bhashas;

2) the rise and development of a new craft, i.e. that of translating into English as a non-native language on the part of Indian translators;

3) the occasionally manipulative essence of this new craft, whereby, in line with more generalized, global tendencies, translations from Indian languages into English seem to have a right to smooth out or change textual features to better go with the English version;

4) the development of Indian English literature as a sort of companion to translation from the Indian languages into English.

These new trends and activities have accompanied India from the colonial days, through to decolonization and a long postcolonial era, designing a series of new paths in translation and writing practices which, although all characterized by the hegemonic role of English, had the merit of expanding the overall range of activities. However, merit has not come without demerit: the increasingly hegemonic role of English has jeopardized the production and dissemination of works into the Indian languages and, most importantly, using English as a recipient of virtually all translations in India has often involved (see point 3 above) condescending to manipulation.

A remark on this attitude is offered by Mukherjee in his clear-cut, earnest style:

There is a regrettable tendency among translators into English, of both foreign and native species, to interfere with the original text in various ways while translating, out of the earnest desire to improve upon the original. There is a measure of hegemony involved here. Even after more than half a century of conscious decolonisation, the English language continues to hold such a position of authority in modern India that those who translate literary works into English somehow convince themselves that they are doing a favour to the Indian language writer by presenting him or her through translation to a wider world. In return for such service, some of our translators feel free to chop and change, omit or rearrange the original to their own satisfaction. (2004: 41)

In the excerpt above, Mukherjee does not lament the hegemonic role acquired by English in India with reference to translation and new writing. What he does, and not without a touch of bitter irony, is point out that the status and role of English have resulted in a generalized, manipulative attitude on the part of translators. This attitude could be seen as the reverse of the essence of transcreation: positive, 
constructive creativity, whose ultimate goal was the full enjoyment of texts by a variety of peoples, has turned into a political and ideological hegemony, which has led to manipulating Indian texts, smoothing out their features to streamline them with global, English-driven tendencies.

However, the role and status of English have also had some positive implications. They have allowed for a much wider dissemination of Indian texts, and led many an Indian writer to produce texts directly in English. And if this latter tendency does retain some nuances of hegemony - English, rather than the Indian languages, is frequently used as a means of expression - it also brings about a number of advantages. This and other attitudes will be further discussed in the next section, where some of Mukherjee's reflections will be analysed and observed along with the thoughts of major Western translation scholars.

\section{More than Mukherjee's eyes: postcolonial translation theories in India and the West}

Looking at contemporary Western translation theory for parallels with Sujit Mukherjee, his work and his ideas about translation, the first figure that comes to mind is Lawrence Venuti, an American with Italian origins. Like Mukherjee, Venuti is a writer, a translator and a translation scholar. Interestingly, although born in different corners of the world, both authors/theorists/translators have worked mainly in English: Lawrence Venuti translates from Italian into English, and English was the main target language for most of Mukherjee's translations.

While English is his mother tongue, Lawrence Venuti feels uneasy about the manipulative tendency which too often accompanies translations into English. In several books on translation $(1995,2008)$, Venuti calls for an ethics of difference, for the visibility of the source text and the sociocultural, linguistic nuances it is made of. He denounces the homogenizing fluency which characterizes virtually all translations from any language into English; these are, in any case, too limited in number if compared with the bulk of translations from English. Through these and other similar statements, he casts light on another global phenomenon which contributes to the hegemony of English worldwide: works written in English tend to be more frequently the object of translation into other languages. English generates translations, not so much translators. 
All in all, whatever the translation direction, Venuti and Mukherjee agree on supporting difference in translation. In fact, Venuti advocates what he calls minoritizing translation (2008), whereby translating from all other languages into English is to be performed not in the name of homogenization and neutralization but of visibility of the source language/culture/society.

Can a translation ever communicate to its readers the understanding of the foreign text that foreign readers have? Yes, I want to argue, but this communication will always be partial, both incomplete and inevitably slanted towards the domestic scene. It occurs only when the domestic remainder released by the translation includes an inscription of the foreign context in which the text first emerged. (Venuti, 2008: 487)

Venuti calls for the visibility of the foreign, the feeling of estrangement which may be evoked by a non-domestic context even through English translation. He also, as in the quotation below, adds a utopian note to translation. Utopian, and not dystopian: the creation of a new community around a translated text, its true appreciation by readers of a different language, are to be pursued in all acts of translation.

Translating is always ideological because it releases a domestic remainder, an inscription of values, beliefs and representations linked to historical moments and social positions in the receiving (but also, I think, in the source) culture. $[\ldots]$

Yet translating is also utopian. The domestic inscription is made with the very intention to communicate the foreign text, and so it is filled with the anticipation that a community will be created around that text, although in translation. (2008: 498)

Another Western scholar who has deeply reflected on the need to preserve difference in and with translation is Michael Cronin. Although embedded in a Western setting, his education and life experiences are very close to that of Sujit Mukherjee: he grew up in Ireland, and has lived through postcolonialism and linguistic and cultural hegemony (English over Irish). In several of his works (2003, 2006), Michael Cronin calls for micro-cosmopolitanism, i.e. an attitude in translation which seeks to develop an eye for the myriad fractal complexities of the local while 
remaining aware of larger contexts. Erasing difference and localism is, to Cronin, equal to moving out of space into non-space.

Marc Augé speaks of certain places as 'non-lieux', 'non-places', where a non place is a space lacking the symbolic expressions of identity, relations and history. Let us argue for the importance of translation in combating the collapse of what might be defined as a polyglossic civility. What we wish to suggest here is that symbolic expressions of identity, relations and history are powerfully, though not exclusively, expressed through language.

[...] If we do not fight the censorship of indifference, our metropolises will run the risk of being colourful juxtapositions of ethnic eateries rather than translation complexes where different language communities both translate and are translated. The bi-directionality is crucial, as otherwise we fall back on the asymmetrical complacency of the strong who may tolerate the products but not the process of translation. In other words, the dominant may put up with translations, not with being translators. (2003: 100)

One of the most striking and valuable features of the excerpt above is Cronin's relocation of the call for an ethics of difference in translation on a geographical level. With a suggestive reference to urban settings and the need to preserve their uniqueness and micro-complexities, he warns against the risks of linguistic and cultural asymmetry, whereby the dominant erases the less powerful. With a few evocative words, he outlines the dangerous potential of hegemonic relations in translation, whereby the strongest accepts translation but does not accept being a translator.

Within the context of India after colonization, Cronin's statements are very much in line with Mukherjee's most mature reflections. The ever-growing flux of translations into English from the Indian languages should strive to preserve and disseminate India's cultural, social and linguistic complexity. English ought to be seen, and used, as an instrument in the hands of Indian translators, rather than be allowed to smooth out diversity.

Reflecting on his own translational activity, Mukherjee observes that English in his translations serves the specific purpose of enhancing dissemination of Bangla texts: 
[...] while converting the language medium (originally Bangla) to English, I seek to replace the target audience (originally the Bengali reader) not so much with the English reader but with the reader of English. (2004: 40)

In an interesting essay called "Transcreating translation," Mukherjee pushes his exploration of the rise and development of Indian writing in, and translating into English further. After outlining the limitations, he emphasizes - as suggested in the quotation above - the positive effects of the use of English. Translation as a practice has, in his words, become the very object of transcreation. As has happened elsewhere, ${ }^{4}$ the language of the colonizer, besides engendering processes of homogenization and endangerment of national languages, lends itself to the growth of a new literary and cultural tradition, born precisely out of postcolonialism - a new trend which allows for the re-, or trans-creation of translation practices. As Mukherjee observes, with reference to our days, English is no longer a foreign language in India. It now belongs to the Indians, who are well capable of bending it to their own purposes.

The English language has got so domesticated that Indians not only translate Indian language texts into English but they are also writing poetry, fiction and drama in English even when they have lived much of their lives in India. $(2004,46)$

The transcreation of translation practices with the advent of English is, for Mukherjee, best exemplified by P. Lal and his work. A translator and translation theorist himself, Lal is well known within and outside India for revamping, in the 1970s, the term 'transcreation' with reference to creative translation in India. And Lal has indeed been a transcreator, within the contemporary framework of Indian translation into English. As Mukherjee reports:

As for P. Lal's own efforts, at least 22 titles in English translation can be attributed to him. Twelve of these are from Sanskrit, one from Pali, two from Bangla, five from Hindi, one each from Urdu and Punjabi. (2004: 44)

\footnotetext{
${ }^{4}$ With reference to Brazil, see the reflections provided by Haroldo De Campos, and also the report by Else Ribeiro Pires Vieira (1999). With reference to China, see, among others, Eva Hung's essay "Collaborative translation - or what can we learn from the Chinese translation tradition" (2002).
} 
Translation, in Lal's practice and in Mukherjee's words, becomes a tool for recovery - the recovery of texts written in India before and after colonization, and their recreation to a new life in English.

Thus, English and translation into English have a unique potential for the dissemination of cultural and linguistic complexity, according to an agenda which is developed within Indian borders and through translations performed by Indian translators. From this viewpoint, translators are no longer to be seen in Cronin's terms as perpetrators of submission to a dominant language and culture; they become active, creative agents in a process which can upturn asymmetries and redesign the ethics of difference through translation.

This is what a third and final outstanding Western scholar, Maria Tymoczko, here called into play, states in Expanding Translation, Empowering Translators (2007):

Dominant models of translation assume that a translator must "know" the languages and cultures involved in moving between a source and target text, but translation in postcolonial contexts challenges this view, showing that the work of translators has a fundamental epistemological dimension. The epistemological component is central to the translator's agency and it has an ethical inflection. Translation does not merely reflect existing knowledge: it can precede knowledge and create knowledge. (197)

This and the other quotes provided in this third section, from Mukherjee, Venuti, Cronin and Tymoczko, have helped us draw a fairly exhaustive map of the turns taken by translation in India after the British conquest. Starting from the abrupt changes brought about by early colonization, the dismissal of transcreation in the old, all-Indian sense and the increasing influence of English in translation and new writing, we have traced the new face and role of the English language, and the new processes of transcreation it has recently brought about.

English today is no longer seen mainly as a threat, a tool for reinforcing asymmetry and for erasing cultural specificity. By virtue of its being one of India's official languages, English is seen as a ductile, creative tool in the hands of Indians. If elements of hegemony are still present in translation practices within India, a lot more is happening through/thanks to English, so that perhaps in a few decades a new translation landscape will take shape. Languages, like translations, are never fixed. And this is precisely what Sujit Mukherjee suggests in one of his most 
powerful statements about translation, which is here provided as a "semi-final" conclusion to this essay:

Finally, when is a translation over and done with? Here is an area in which the translated work enjoys an enormous advantage over the original. The original tends to get fixed in form as soon as it becomes widely known. Famous authors have, of course, revised even their published works. But no revision can ever match the free hand with which a translator can redo his or her own translation or re-translate a text that has been done earlier. Translation bestows an indefinitely long life upon a text whose original career may have terminated much earlier had it not drawn a translator's attention. The truly crafty translator will know why he translates, for whom he translates, what he should translate, how much to translate and, semi-finally, when to stop. (2002: 34) 


\section{REFERENCES}

Bollettieri, Rosa Maria, and Elena Di Giovanni. Oltre l'Occidente. Tradurione e Alterità Culturale. Milano: Bompiani, 2009.

Cronin, Michael. Translation and Globalization. London/New York: Routledge, 2003.

-----. Translation and Identity. London/New York: Routledge, 2006.

Das, Samantak. "Multiple Identities: Notes towards a Sociology of Translation". Translation, Text and Theory: the Paradigm of India. Ed. Rukmini Bhaya Nair. New Delhi: Sage, 2002. 35-45.

De Campos, Haroldo. "The Rule of Anthropofagy: Europe under the Sign of Devoration." Latin American Literary Review 14.27 (1986) 42-60.

Di Giovanni, Elena. "L'India in Italia Attraverso il Cinema: Traduzione e Transcreazione." Lessicologia e Metalinguaggio. Ed. Diego Poli. Roma: Il Calamo, 2007. 473-494.

Gopinathan G. "Translation, Transcreation and Culture. Theories of Translation in Indian Cultures." Translating Others (Vol. 1). Ed. Theo Hermans. Manchester: St. Jerome Publishing, 2006. 236-247.

Hung, Eva. "Collaborative Translation - or What Can We Learn from the Asian Translation Tradition?" Translation and Contrastive Studies. Ed. Wenguo Pan. Shanghai: Waiyu Jiaoyu Pub. Co., 2002. 21-45.

Khilnani Sunil. The Idea of India. New Delhi: Penguin Books India, 1997.

Kumar, Ravi, ed. Role of Translation in Nation Building. New Delhi: Modlingua, 2013.

Mukherjee, Sujit. Translation as Discovery. And Other Essays on Indian Literature in English Translation. New Delhi: Allied Publishers, 1981.

-----. "Personal Commitment: the Craft not Sullen Art of Translation." Translation, Text and Theory. The Paradigm of India. Ed. Rukmini Bhaya Nair. New Delhi: SAGE, 2002. 25-35. 
Translation as Recovery. New Delhi: Pencraft International, 2004.

Ribeiro Pires Vieira, Else. "Liberating Calibans. Readings of Antropofagia and Haroldo de Campos' poetics of transcreation.” Post-colonial Translation Studies. Theory and Practice. Eds. Susan Bassnett and Harish Trivedi. London/New York: Routledge, 1999. 95-113.

Trivedi, Harish. "Introduction." Translation as Recovery. Sujit Mukherjee. New Delhi: Pencraft International, 2004. 11-20.

Tymoczko, Maria. Enlarging Translation, Empowering Translators. Manchester: St. Jerome Publishing, 2007.

Venuti, Lawrence. The Translator's Invisibility. A History of Translation. London/New York: Routledge, 1995.

-----. The Scandals of Translation. London/New York: Routledge, 2008. 